\title{
EXAMINING THE ADEQUACY OF AN EXIT EXAM TO MEASURE DIPLOMA STUDENTS' ACHIEVEMENT: RASCH ANALYSIS

\author{
Enas S. Abulibdeh ${ }^{1 *}$, Kamal J I Badrasawi ${ }^{2}$, Noor Lide Abu Kassim ${ }^{3}$ \\ ${ }^{1 *}$ Assistant Professor, Al Ain University, UAE; ${ }^{2}$ Assistant Professor, International Islamic University Malaysia, Malaysia; \\ ${ }^{3}$ Professor, International Islamic University Malaysia, Malaysia.
} \\ Email: ${ }^{1 *}$ enas.abulibdeh@gmail.com, ${ }^{2}$ kamalbadrasawi@iium.edu.my, ${ }^{3}$ noorlide@iium.edu.my
}

Article History: Received on $2^{\text {nd }}$ February 2020, Revised on $18^{\text {th }}$ July 2020, Published on $27^{\text {th }}$ September 2020

\begin{abstract}
Purpose of the study: This paper examines the adequacy of an exit exam using the Rasch Model. It also addresses the students' achievement on the exam items according to Learning Outcomes (LOs) i.e. what LOs have been achieved and have not been achieved.

Main Findings: The Rasch analyses showed that there were issues related to the adequacy of the exit exam in terms of the items' validity and items' distribution along the interval scale. The items' qualitative investigation revealed that the stems and options of some items have problems. Overall, the exam was easy for the students, and students scored different achievement according to Learning Outcomes (LOs). These findings highlight the importance of using measurement models to validate exams as well as to provide a more accurate interpretation of students' achievement; Rasch Model is an example.
\end{abstract}

Methodology: The descriptive quantitative research design was utilized to achieve the research objectives. An exam comprises 100 Multiple choice items/questions administered to 322 students taking Professional Diploma in Teaching at a College of Education. The items cover eight 8 Learning Outcomes that students were expected to achieve when completed all the Professional Diploma courses. The collected data were analyzed using the Rasch Model for dichotomous data, and Winsteps software 4.1.0 (2018).

Applications of this study: The study provides insightful information to higher institutions in general and to colleges of education to revamp the implementation of diploma teaching programs, mainly the assessment methods.

Novelty/Originality of this study: This paper extends the evidence of providing academic staff at higher institutions with necessary information and training on measurement to come out with more informed decisions.

Keywords: Dichotomous Data, Exit Exam, Rasch Model Analysis, Students' Abilities and Achievement.

\section{INTRODUCTION}

Measurement and evaluation are key components of the whole teaching and learning process as they provide information related to students' learning progress or performance (Worthen, White, Fan \& Sudweeks, 1999). In most academic institutions, tests are the most common instruments used to measure students' performance and then make decisions based on their test scores. Such tests have increasingly been criticized due to shortcomings in their appropriateness in terms of preparation, selection, administration, and interpretation of the results (Worthen et al., 1999). They further asserted that there should be "some structured, reliable way to measure student performance" to ensure that students are being taught effectively. In other words, examiners should use a measurement model that helps them ensure the test appropriateness and provide more accurate/reliable interpretations of the test results in a practical way. Linacre (2003) elaborated that "the more generally applicable the model, and the more useable the results, the more it is likely to meet practical needs and form the basis for scientific progress" (p. 907). This was previously highlighted by Wright (1997), who mentioned that if our decisions were based on untrustworthy measures and divergent units, then the decisions are inaccurate. For instance, using test raw scores to determine students' performance in a specific subject is not enough as they do not reflect the intended results and provide spurious or "misleading information and distortion" (Lee, 2002; Wright, 1993a; Wright, 1999; Wright \& Linacre, 1997).

The Rasch Measurement Model, named after George Rasch, a Danish mathematician, helps get more accurate and reliable measurements for students' abilities or performances (Bond \& Fox, 2015; Engelhard 2000; Linacre, 2003; Wright \& Stone, 1979). The model is used for assessment in psychology, education, health, and physical science. In principle, it attributes the likelihood of getting an accurate answer to a particular item to the difference between person ability and item difficulty. This means that the correct answer is dominated by item difficulty and person ability. Two propositions underlie the theoretical concept of the Rasch Measurement Model (Bond \& Fox, 2015). First, skilled examinees are more likely to answer all items correctly. Second, all examinees can likely answer easier items correctly. This formula shows the probabilistic dichotomous model:

$$
\mathbf{P} n i\{x n i=1 \mid \mathbf{B} n, \mathbf{D} i\}=\exp (\mathbf{B} n-\mathbf{D} i) /[1+\exp (\mathbf{B} n-\mathbf{D} i)]
$$


Where:

$\mathbf{P} n i\{\mathrm{x} n i=1 \mid \mathbf{B} n, \mathbf{D} i\}$ is the probability of person on item $(i)$ scoring a correct response $(\mathrm{x}=1)$ rather than an incorrect response ( $\mathrm{x}=0$ ), given person ability $\mathbf{B} n$ and item difficulty $(\mathbf{D} i)$. This probability is equal to the constant e, or natural log function (2.7183) raised to the difference between a person's ability and item's function (Bn-Di), divided by 1 plus this same value (Bond \& Fox, 2015).

Among the uses of the Rasch Measurement Model are to validate tests, ensure test equivalence using common item equating i.e. make sure that the tests are comparable if different tests are used every year, and display students' levels of ability and items difficulty on a same interval scale. Boone (2016) pointed out that Rasch analysis is a psychometric technique used to ensure the precision that researchers need to "construct instruments, monitor instrument quality, and compute respondents' performances" (p.1). The same ideas were earlier iterated in (Curtis \& Boman, 2007; Ingebo, 1997; Kimberlin \& Winterstein; 2008). Therefore, this paper addresses the adequacy of an exit exam using the Rasch Measurement Model (RMM). Particularly, the analysis presents the (1) validity of test items, (2) construct validity, (3) capacity of the test to produce results that are consistent with the purpose of the measurement, and (4) validity of student responses. It also shows all the students' achievement on the exam items according to Learning Outcomes (LOs) i.e. what LOs have been achieved and have not been achieved. The Rasch analysis was conducted using Winsteps statistical software, version 4.1.0 (Linacre, 2018).

\section{RESEARCH METHOD}

This is quantitative research utilized the descriptive approach that is often used to describe data and characteristics related to issues being investigated in research using certain instruments such as questionnaires, tests, self-reports, observations, etc. (Creswell, 2014; Gay \& Airasian, 2012). In this research, an exam instrument was used to assess the students' achievement in the courses they had taken in a professional diploma in Teaching at a College of Education. This exam is usually conducted at the end of the Teaching Diploma program for the students who complete all the program courses. The exam consisted of one hundred (100) MCQ items meant to assess eight (8) Learning Outcomes (LOs) according to the courses taught to the students. More specifically, it included 14 items for the learning outcome "Plan and design an effective student-centered learning environment (PD); 13 items for "Demonstrate knowledge of content and pedagogy necessary for effective instruction in their field of study (KCM)"; 13 items for "Demonstrate knowledge of their students' characteristics (KCH)"; 13 items for "Apply a research-utilized multi-methodology approach and make any necessary changes or adaptations of their teaching strategies based upon an ongoing assessment process (APP)"; 14 items for "Develop constructive communication skills with their students, parents, school administrators, and colleagues to solve problems and enhance students' learning (DCOM)"; 13 items for "Conduct an ongoing assessment/evaluation of student learning. (EV)"; 10 items for "Use or Apply information and communication technology tools in instructional planning, delivery of instruction, and in the assessment of students' learning (TECH)"; and 10 items for "Demonstrate professional responsibility towards their students, school and society (PR)". It is worthwhile to add the exam content validity would not be an issue because content experts/lecturers usually construct the items of this type of exam. Meanwhile, the measurement requirements of the exam were thoroughly explained in the discussion section as one of the research objectives was to address the adequacy of the test using the Rasch Model and Winsteps software, version 4.1.0. (2018). It discusses the validity of exam items, constructs validity, the capacity of the exam to produce results that are consistent with the purpose of the measurement and validity of student responses. Three hundred and twenty students (320) of Professional Diploma in Teaching at a College of Education answered the exam items, and all of them were included in the Rasch Model final analysis. All the results were presented in Tables and Figures.

\section{RESULTS AND DISCUSSION}

\section{Adequacy of Exit Exam}

The following analyses show the validity of exam items, construct validity, the capacity of the exam to produce results that are consistent with the purpose of the measurement, and the validity of student responses.

For the exam items validity, three indicators were used Item polarity, Item Fit, and Unidimensionality. Item polarity indicates to what extent all the items in a given test are in the same direction to measure the measured construct. Negative or zero value items mean that the answers to these items are in conflict with the other items included in the test. Therefore, items with high positive values (0.3-0.8) are desired (Linacre, 2019). Items below 0.3 show that items are not discriminating against the examinees effectively. Table A1 shows the point measure correlation (PTMEA CORR.) for the 100 items. The results indicate that three items (App 43, PR 98, and DCOM59) had negative point measure correlation coefficients (-.12, .07 , and -.02) respectively. This means that the items were not defining the measured construct in the same direction as other items. There is another possibility that the examinees are not responding to these items as the model expected because these items were very difficult or there were issues about the items construction and the options. Deleting the unexpected 
responses (with the Outfit MNSQ) above 1.3 did not improve the correlation coefficients. However, the qualitative investigation for the three items referred to certain issues (related either to items' stems or their options). For example, item APP 43 might have more than one possible answer; and the same has happened to item DCOM 98; whereas item PR 98 has no possible correct answer. This is supported by the item difficulty measures and item category options frequencies (percentages) (Appendix A1). All other items had positive point measure correlation coefficients, but the majority were below 0.3 (between $0.01 \leq 0.30$ ). These three items and items with low point measure correlation coefficients, $<0.20$ were plotted with items that had correlation coefficients $\geq 0.20$. Figure 1 shows all the items were between the interval lines, indicating that all the items were in the same direction in measuring the same construct.

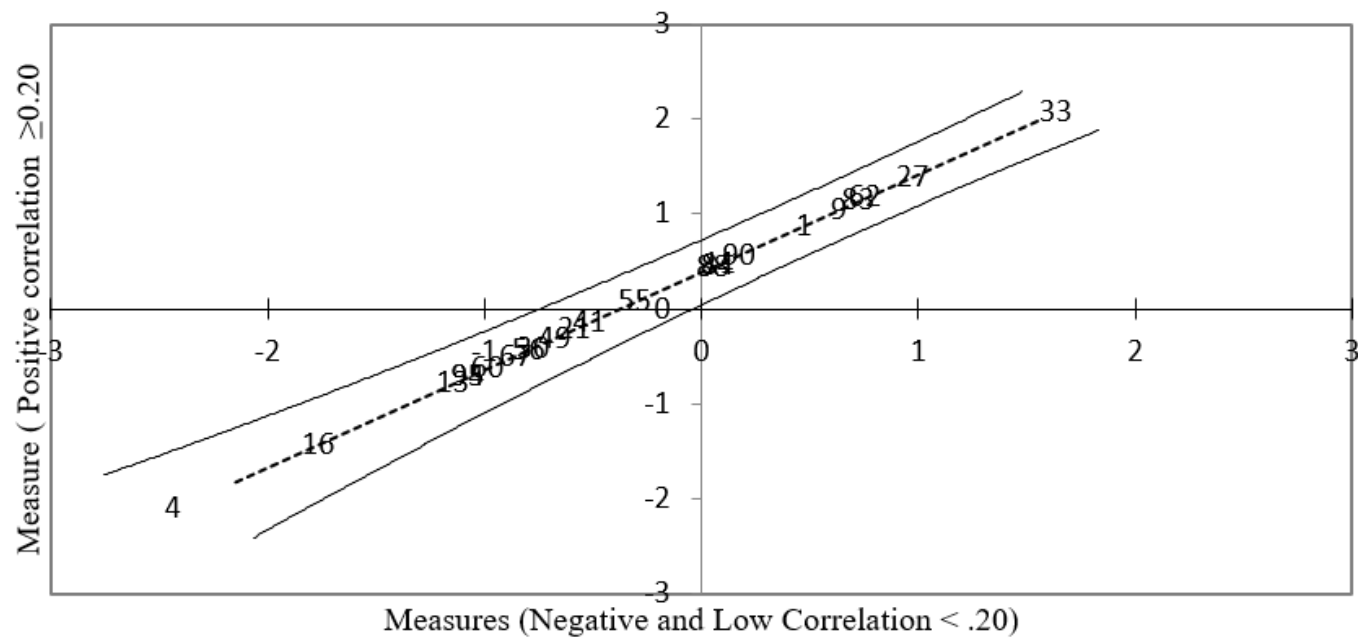

Figure 1: Cross Plot: Item Measures Based on Item Correlations

Fit statistics are investigated to ensure the items are contributing meaningfully to the measured construct. The two major fit statistics (the infit and outfit Mean-square statistics) were used (Bond \& Fox, 2015; Boone, 2016; Green \& Frantom, 2002). The recommended range for multiple-choice items is (0.7-1.3) (Bond \& Fox, 2015). Table A1 shows the infit and outfit mean square of individual items. All items were within the recommended infit and outfit mean-square range $(0.7-1.3)$, except two items (PR 98 and APP 43) with Outfit mean square above 1.3. The two items had issues in their writing as discussed earlier. The mean score for the infit mean square was $(1.00$ logit) while it was $(.99$ logit) for the Outfit mean square, almost the expected value of (1.00 logit). However, the standard error measurement for the individual items ranged between (.12-.32), indicating that some items might not function effectively (See Appendix A1).

Unidimensionality is used to denote that the items of a given test measure a single unidimensional construct, and it is measured by using the principal component analysis of residuals. Table A1 demonstrates that Unidimensionality is supported. However, the raw variance explained measure was low $(25.7 \%)$. There is no secondary dimension since all the factors in the first and second contrasts were less than 5\%. Moreover, the largest factor extracted from the residuals was equivalent to 2.67 .

The reliability of the difficulty of the items was quite high at (0.99) as seen in Table A1, which indicates the possibility to replicate the ordering of item difficulty with similar groups of students. The item separation index was 8.34, indicating that the items can be divided into at least 8 difficulty levels, which is satisfactory for 100 items. However, the distribution of the items on the map showed that there were two gaps at the end and bottom parts of the scale. In addition, some clusters of items appeared in the middle (Figure 2). The qualitative investigation showed that there were issues with items that made the majority of students not to get the correct answers. Table 1 also shows that the reliability of the examinees' ability measure was not high (0.77), which suggests that the likelihood of replicating the students ordering with other items of the same difficulty would not be high. The examinees' separation index was 1.85 , showing that the examinees could be split into two levels of ability. The results showed that in general examinees were not answering as the model expected, supported by the high value (.24) for the measurement standard error (Figure 3).

Table 1: Item statistics of 100 Exam Items

\begin{tabular}{llllllllllll}
\hline $\begin{array}{l}\text { Item } \\
\text { Entry }\end{array}$ & $\begin{array}{l}\text { Difficulty } \\
\text { measures }\end{array}$ & S.E & $\begin{array}{l}\text { Infit } \\
\text { MNSQ }\end{array}$ & $\begin{array}{l}\text { Outfit } \\
\text { MNSQ }\end{array}$ & $\begin{array}{l}\text { PT-M } \\
\text { CORR }\end{array}$ & $\begin{array}{l}\text { Item } \\
\text { Entry }\end{array}$ & $\begin{array}{l}\text { Difficulty } \\
\text { measures }\end{array}$ & S.E & $\begin{array}{l}\text { Infit } \\
\text { MNSQ }\end{array}$ & $\begin{array}{l}\text { Outfit } \\
\text { MNSQ }\end{array}$ & $\begin{array}{l}\text { PT-M } \\
\text { CORR }\end{array}$ \\
\hline PD1 & 1.08 & 0.12 & 1.07 & 1.09 & 0.09 & DCOM54 & 0.02 & 0.12 & 0.99 & 1.01 & 0.24 \\
\hline PD2 & -0.31 & 0.13 & 1.07 & 1.14 & 0.07 & DCOM55 & -0.12 & 0.12 & 1.08 & 1.14 & 0.06 \\
\hline
\end{tabular}


https://doi.org/10.18510/hssr.2020.82e22

\begin{tabular}{|c|c|c|c|c|c|c|c|c|c|c|c|}
\hline PD3 & 1.39 & 0.12 & 1.06 & 1.09 & 0.10 & DCOM56 & -1.44 & 0.18 & 1.01 & 1.08 & 0.14 \\
\hline PD4 & 1.47 & 0.12 & 1.05 & 1.10 & 0.11 & DCOM57 & 0.02 & 0.12 & 0.97 & 0.96 & 0.30 \\
\hline PD5 & -0.7 & 0.14 & 0.97 & 0.96 & 0.27 & DCOM58 & 0.82 & 0.12 & 0.98 & 0.97 & 0.29 \\
\hline PD6 & -0.6 & 0.14 & 0.99 & 0.97 & 0.24 & DCOM59 & 1.86 & 0.13 & 1.10 & 1.20 & -0.02 \\
\hline PD7 & 0.14 & 0.12 & 0.97 & 0.97 & 0.29 & DCOM60 & -1.79 & 0.20 & 1.01 & 1.09 & 0.11 \\
\hline PD8 & -0.23 & 0.13 & 0.95 & 0.93 & 0.33 & DCOM61 & -0.25 & 0.13 & 1.03 & 1.02 & 0.18 \\
\hline PD9 & -0.49 & 0.13 & 1.06 & 1.07 & 0.10 & DCOM62 & 0.47 & 0.12 & 1.03 & 1.03 & 0.19 \\
\hline PD10 & 0.12 & 0.12 & 0.98 & 0.98 & 0.27 & DCOM63 & -1.67 & 0.19 & 0.93 & 0.76 & 0.34 \\
\hline PD11 & -0.9 & 0.15 & 1.00 & 1.03 & 0.19 & DCOM64 & -1.57 & 0.18 & 0.99 & 0.95 & 0.20 \\
\hline PD12 & 0.53 & 0.12 & 0.98 & 0.98 & 0.27 & DCOM65 & -1.18 & 0.16 & 0.94 & 0.96 & 0.29 \\
\hline PD13 & 2.18 & 0.14 & 1.01 & 1.12 & 0.13 & DCOM66 & 2.34 & 0.15 & 0.95 & 0.92 & 0.28 \\
\hline PD14 & 0.69 & 0.11 & 0.97 & 0.97 & 0.29 & DCOM67 & 0.48 & 0.12 & 1.03 & 1.04 & 0.18 \\
\hline KCM15 & -2.33 & 0.25 & 0.95 & 0.63 & 0.31 & EV68 & -0.53 & 0.13 & 0.95 & 0.89 & 0.34 \\
\hline KCM16 & 0.17 & 0.12 & 1.03 & 1.05 & 0.18 & EV69 & -2.90 & 0.32 & 0.95 & 0.56 & 0.29 \\
\hline KCM17 & -0.9 & 0.15 & 0.97 & 1.00 & 0.24 & EV70 & 1.68 & 0.13 & 1.03 & 1.08 & 0.13 \\
\hline KCM18 & 0.05 & 0.12 & 1.03 & 1.06 & 0.17 & EV71 & -0.74 & 0.14 & 0.95 & 0.89 & 0.33 \\
\hline KCM19 & -0.99 & 0.15 & 0.99 & 0.97 & 0.22 & EV72 & 0.07 & 0.12 & 1.07 & 1.07 & 0.11 \\
\hline KCM20 & -1.06 & 0.15 & 0.9 & 0.77 & 0.42 & EV73 & -0.33 & 0.13 & 0.99 & 0.99 & 0.24 \\
\hline KCM21 & 0.74 & 0.11 & 1.03 & 1.03 & 0.18 & EV74 & 0.36 & 0.12 & 0.97 & 0.96 & 0.30 \\
\hline KCM22 & 0.78 & 0.11 & 0.97 & 0.97 & 0.29 & EV75 & -2.05 & 0.22 & 0.95 & 0.88 & 0.24 \\
\hline KCM23 & -0.44 & 0.13 & 0.95 & 0.92 & 0.32 & EV76 & 1.49 & 0.12 & 0.96 & 0.95 & 0.30 \\
\hline KCM24 & -0.72 & 0.14 & 0.96 & 0.90 & 0.30 & EV77 & -0.64 & 0.14 & 1.00 & 0.97 & 0.23 \\
\hline KCM25 & 1.68 & 0.13 & 0.99 & 0.98 & 0.24 & EV78 & -0.12 & 0.12 & 0.97 & 0.98 & 0.29 \\
\hline KCM26 & 0.24 & 0.12 & 0.99 & 0.97 & 0.27 & EV79 & 1.63 & 0.13 & 1.05 & 1.09 & 0.11 \\
\hline KCM27 & 1.06 & 0.12 & 1.03 & 1.04 & 0.17 & EV80 & 0.02 & 0.12 & 0.92 & 0.90 & 0.40 \\
\hline $\mathrm{KCH} 28$ & 0.61 & 0.11 & 1.05 & 1.05 & 0.15 & TECH81 & -1.29 & 0.17 & 0.94 & 0.88 & 0.30 \\
\hline KCH29 & -0.99 & 0.15 & 0.97 & 0.93 & 0.26 & TECH82 & -1.91 & 0.21 & 0.93 & 0.74 & 0.33 \\
\hline KCH30 & 1.86 & 0.13 & 1.09 & 1.19 & 0.01 & TECH83 & -1.11 & 0.16 & 1.01 & 1.11 & 0.13 \\
\hline KCH31 & 1.02 & 0.12 & 1.01 & 0.01 & 0.22 & TECH84 & 2.38 & 0.15 & 1.05 & 1.21 & 0.03 \\
\hline $\mathrm{KCH} 32$ & -1.67 & 0.19 & 0.98 & 0.92 & 0.20 & TECH85 & 1.00 & 0.12 & 1.08 & 1.11 & 0.08 \\
\hline KCH33 & -1.29 & 0.17 & 1.02 & 1.05 & 0.14 & TECH86 & -0.51 & 0.13 & 0.97 & 0.92 & 0.29 \\
\hline KCH34 & -0.78 & 0.14 & 0.96 & 0.93 & 0.29 & TECH87 & 0.12 & 0.12 & 0.98 & 0.97 & 0.28 \\
\hline $\mathrm{KCH} 35$ & -0.51 & 0.13 & 0.95 & 0.96 & 0.31 & TECH88 & 0.19 & 0.12 & 1.09 & 1.10 & 0.07 \\
\hline KCH36 & 0.15 & 0.12 & 0.99 & 0.99 & 0.25 & TECH89 & 0.51 & 0.12 & 0.99 & 0.99 & 0.26 \\
\hline KCH37 & 0.81 & 0.12 & 1.00 & 1.00 & 0.24 & TECH90 & 0.76 & 0.11 & 1.05 & 1.06 & 0.14 \\
\hline $\mathrm{KCH} 38$ & -0.53 & 0.13 & 0.97 & 0.97 & 0.27 & PR91 & 0.85 & 0.12 & 1.12 & 1.13 & 0.01 \\
\hline KCH39 & -1.16 & 0.16 & 0.95 & 0.88 & 0.29 & PR92 & -0.14 & 0.12 & 1.00 & 1.01 & 0.22 \\
\hline KCH40 & 1.24 & 0.12 & 0.99 & 1.00 & 0.24 & PR93 & 1.64 & 0.13 & 0.98 & 1.00 & 0.25 \\
\hline App41 & -0.99 & 0.15 & 1.01 & 1.12 & 0.13 & PR94 & 3.09 & 0.2 & 1.01 & 1.03 & 0.12 \\
\hline App42 & -0.70 & 0.14 & 0.97 & 0.94 & 0.27 & PR95 & -2.27 & 0.24 & 0.99 & 0.93 & 0.15 \\
\hline App43 & 2.66 & 0.17 & 1.09 & 1.49 & -0.12 & PR96 & -2.47 & 0.27 & 0.93 & 0.67 & 0.31 \\
\hline App44 & -0.58 & 0.14 & 1.00 & 0.94 & 0.24 & PR97 & 0.32 & 0.12 & 0.94 & 0.92 & 0.37 \\
\hline App45 & -0.97 & 0.15 & 0.96 & 0.97 & 0.27 & PR98 & 3.56 & 0.24 & 1.04 & 1.50 & -0.07 \\
\hline App46 & -0.12 & 0.12 & 0.97 & 0.95 & 0.29 & PR99 & 0.29 & 0.12 & 1.05 & 1.05 & 0.15 \\
\hline App47 & 0.1 & 0.12 & 0.99 & 0.97 & 0.27 & PR100 & 0.33 & 0.12 & 0.94 & 0.93 & 0.35 \\
\hline App48 & -0.55 & 0.13 & 0.97 & 0.94 & 0.28 & Means & 0.00 & 0.14 & 1.00 & 0.99 & \\
\hline App49 & -0.33 & 0.13 & 1.10 & 1.14 & 0.02 & \multicolumn{4}{|c|}{ Item Reliability } & 0.99 & \\
\hline App50 & -1.41 & 0.17 & 0.98 & 0.93 & 0.22 & \multicolumn{4}{|c|}{ Item separation } & 8.34 & \\
\hline App51 & -1.32 & 0.17 & 0.94 & 0.83 & 0.32 & \multicolumn{4}{|c|}{ Person Reliability } & 0.77 & \\
\hline App52 & -0.38 & 0.13 & 0.95 & 0.92 & 0.33 & \multicolumn{4}{|c|}{ Person Separation } & 1.85 & \\
\hline App53 & 1.86 & 0.13 & 0.96 & 0.93 & 0.28 & \multirow{2}{*}{\multicolumn{4}{|c|}{$\begin{array}{l}\text { Raw variance explained by measures } \\
\text { Unexplained variance in 1st contrast }\end{array}$}} & $25.7 \%$ & \\
\hline Continu & Entry & aber & & & & & & & & 2.67 & \\
\hline
\end{tabular}

For the construct validity, the scale continuum of increasing intensity was examined. When the items are distributed evenly and there are no significant gaps between the items distribution, the continuum of increasing intensity is achieved. Figure 2 
shows that visible gaps between items distribution were not significant. However, the upper and lower ends of the scale showed two wide gaps, indicating that the most difficult items are at the top and the easiest ones are at the bottom. Most of the items were accumulated around the mean (i.e. in the middle of the scale). This supports that either the items were not discriminating the examinees effectively, or the examinees were with narrow ability range. Qualitative investigations showed that the most difficult items placed at the upper part of the scale had issues in the stem and the options, which made the majority of students, not get the correct answers. The clustered items in the middle should be investigated to see if they were measuring almost the same things. Figure 2 clearly shows the item difficulty measures ordered from the most difficult items (PR 98 (3.56 logit) PR 94 (3.09 logit) to the easiest items (EV69 (-2.90 logit) and PR96 (-2.47 logit).

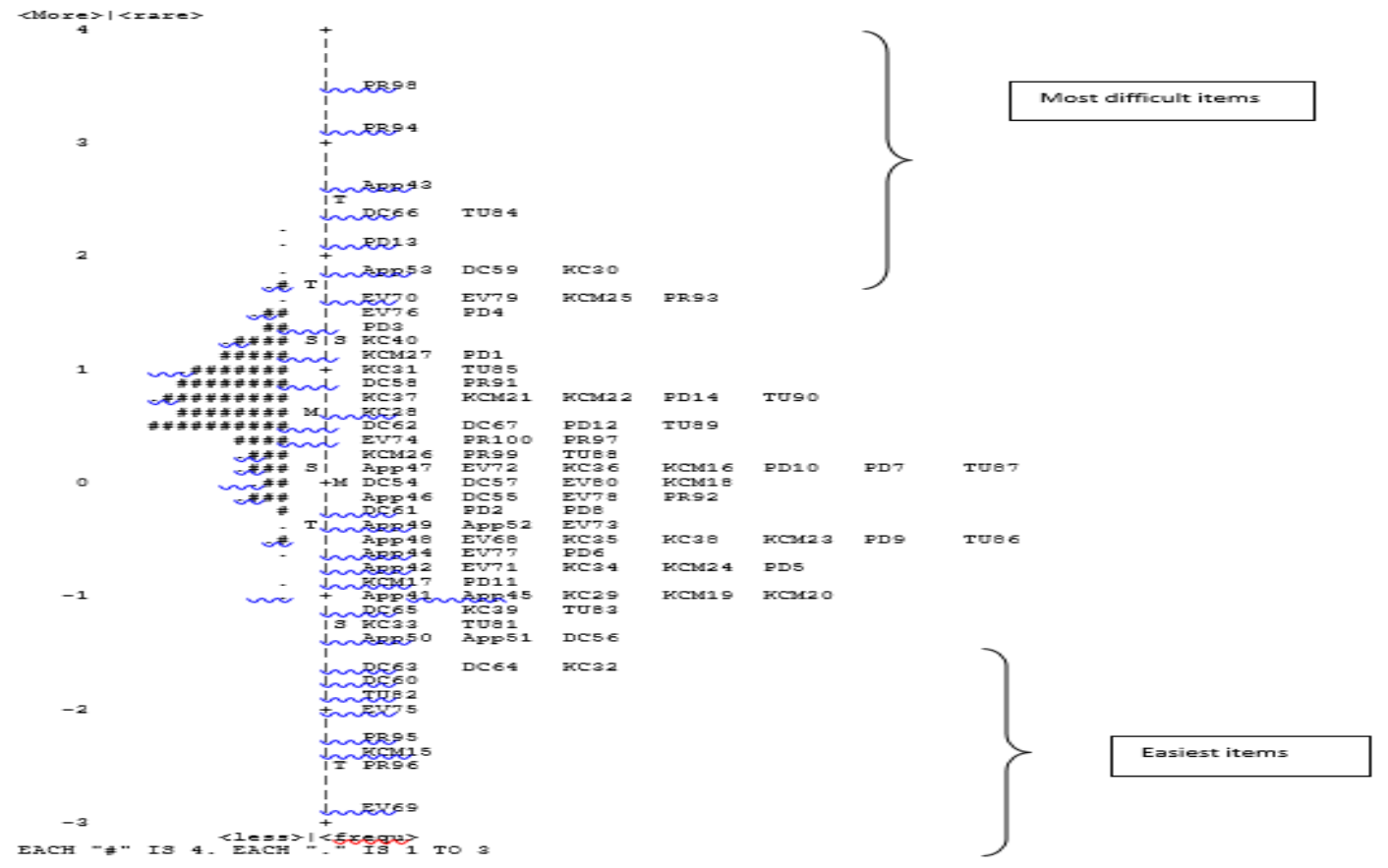

Figure 2: Item-Map

The table in appendix A2 shows the fit statistics of the examinee responses. The infit MNSQ value was 1.00 logit, the expected value of the model (1.00). The Outfit MNSQ (0.99) was close to the value expected by the model. However, the standard error was $(0.24$ logits). Eight students were to be found misfit as their Outfit MNSQ was above the recommended range (.7-1.3). It seems that students were not responding to items as Rasch Model expected, as depicted in Figure 3. One proposed reason for the high misfit statistics is lucky guessing by low achievers and the issues found in some items' options and stems.

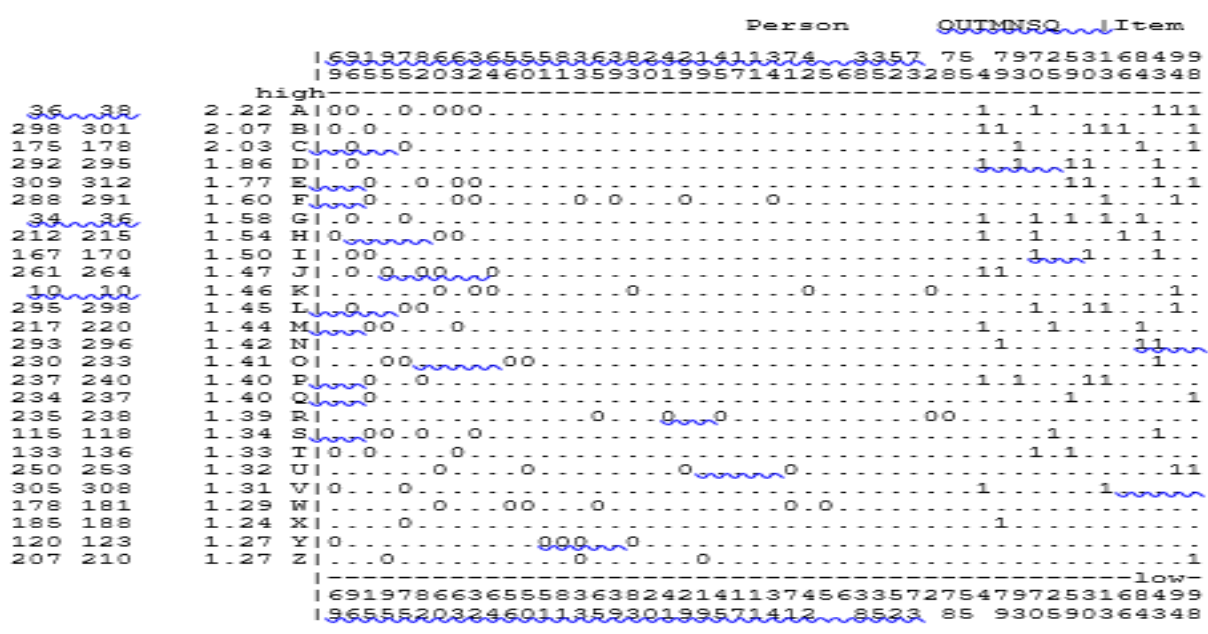

Figure 3: Most Mis-fitting Response Strings 
In general, the results showed that the test might not be adequate to be used to describe the examinees' achievement. There are good items while many others need further qualitative investigation.

\section{STUDENTS' ACHIEVEMENT LEVELS}

The Rasch analyses were conducted to determine the students' achievement levels on the exam items as overall and according to each learning outcome that students were expected to achieve once they completed the courses taught in the professional Diploma in Teaching at a College of Education. Rasch Item and Person Maps can display the positions of Items and Persons on the same interval scales. They help to ensure which learning outcomes have been achieved and yet have not been achieved. In other words, they help to determine how much students have acquired from the courses taken in the program, and in which learning outcomes they showed higher and lower achievement. The Maps can also show the most able students placed at the upper part of the scale and the least able students placed toward the lower part of the scale.

On average, the students' ability as a group was higher than the item difficulty. The students found the exam as easy because the mean score of their ability was 0.67 logit, which is considered quite larger than the mean score of the item difficulty $(0.0)$ (Figure 4). The map shows that items that were correctly answered by the examinees are placed towards the lower part of the scale, while the least correctly answered, are positioned towards the upper part. Moreover, the examinee ability measures spanned about 3.19 logits (from - .99 to +2.20 ) while item difficulty measures spread was about 6.46 logits (from -2.9 to + 3.56). Figure 4 also shows that most students were distributed between -.5 logit and +1 logit, and most of the students are accumulated around the middle of the scale, which means that they almost have a narrow range of ability.

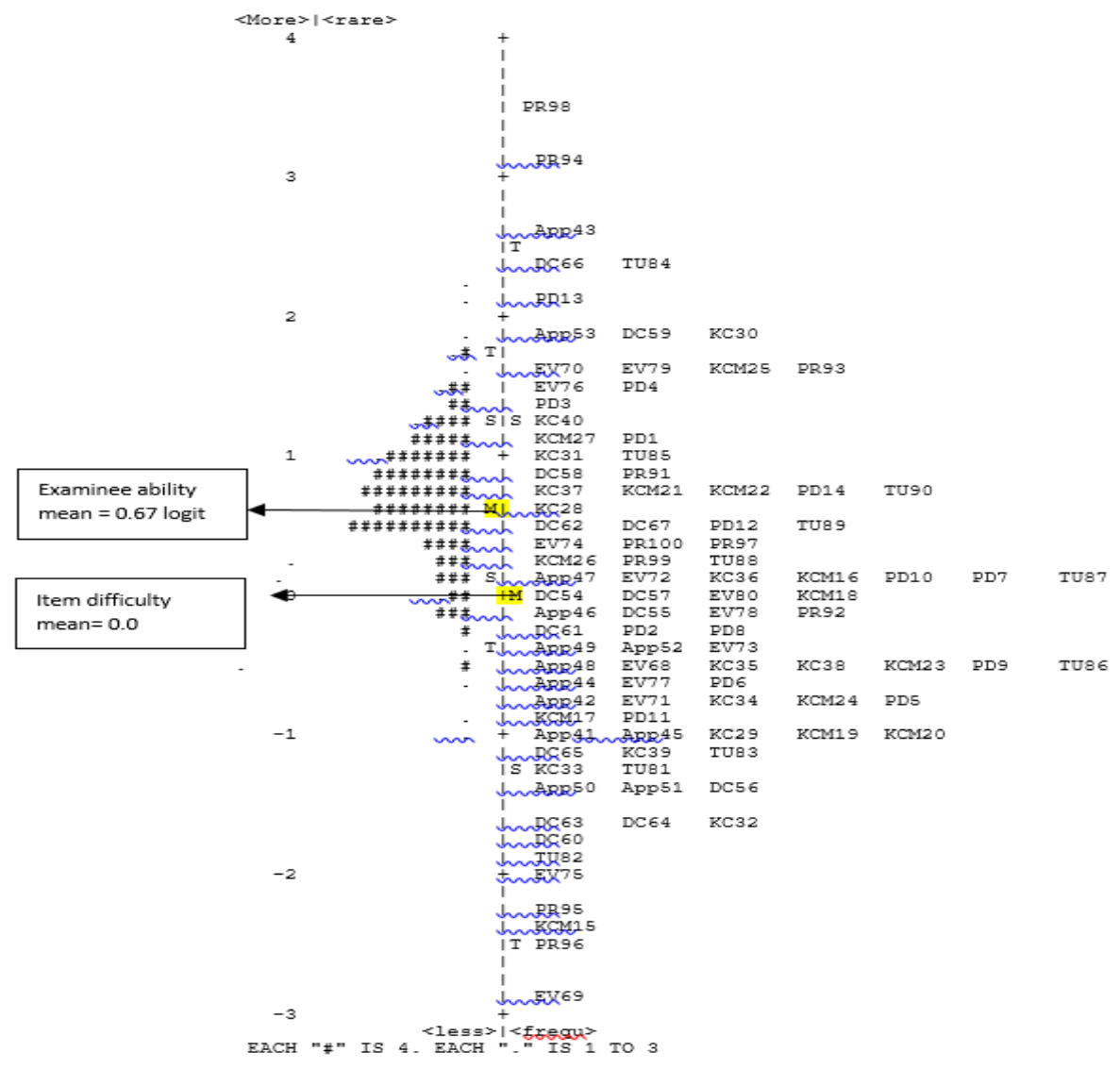

Figure 4: Examinee Ability and Item Difficulty Map

Though in overall it was easy for the students to answer the exam items, it is essential to highlight that students scored different levels according to the learning outcomes that students were expected to achieve when they had finished all the diploma courses. Figure 5 shows the means of each learning outcome items and the distribution and the hierarchical order of items. The most difficult learning outcome for students was "Demonstrate professional responsibility towards their students, school, and society" (PR) ( $\mathrm{M}=0.52$ logits). It is followed by the learning outcome "Plan and design an effective studentcentered learning environment" (PD) $(\mathrm{M}=0.31$ logits), and "Use or Apply information and communication technology tools in instructional planning, delivery of instruction, and in the assessment of students' learning (TECH)" $(\mathrm{M}=0.01)$. Whereas 
the easiest category was related to the learning outcome, "Apply a research-utilized multi-methodology approach and make any necessary changes or adaptations of their teaching strategies based upon an ongoing assessment process" $(\mathbf{A P P})(\mathbf{M}=-$ 0.21 logits). It is followed by "Conduct an ongoing assessment/evaluation of student learning" $(\mathbf{E V})(\mathrm{M}=-0.16$ logits $)$, "Develop constructive communication skills with their students, parents, school administrators, and colleagues to solve problems and enhance students' learning" (DCOM) $(\mathrm{M}=-0.14$ logits), "Demonstrate knowledge of content and pedagogy necessary for effective instruction in their field of study $(\mathbf{K C M})(\mathrm{m}=-0.13$ logits), and Demonstrate knowledge of their students' characteristics "(KCH) $(\mathbf{M}=-0.10)$. However, the items of each learning outcome showed different distributions. Some items were placed at the top while others were placed either in the middle or at the bottom of the measurement scale. Meaning that the students had or had not achieved certain skills under each learning outcome. The students were not able to answer the questions placed at the top correctly, while it was easy for them to answer the question at the bottom correctly as displayed in Figure 5.

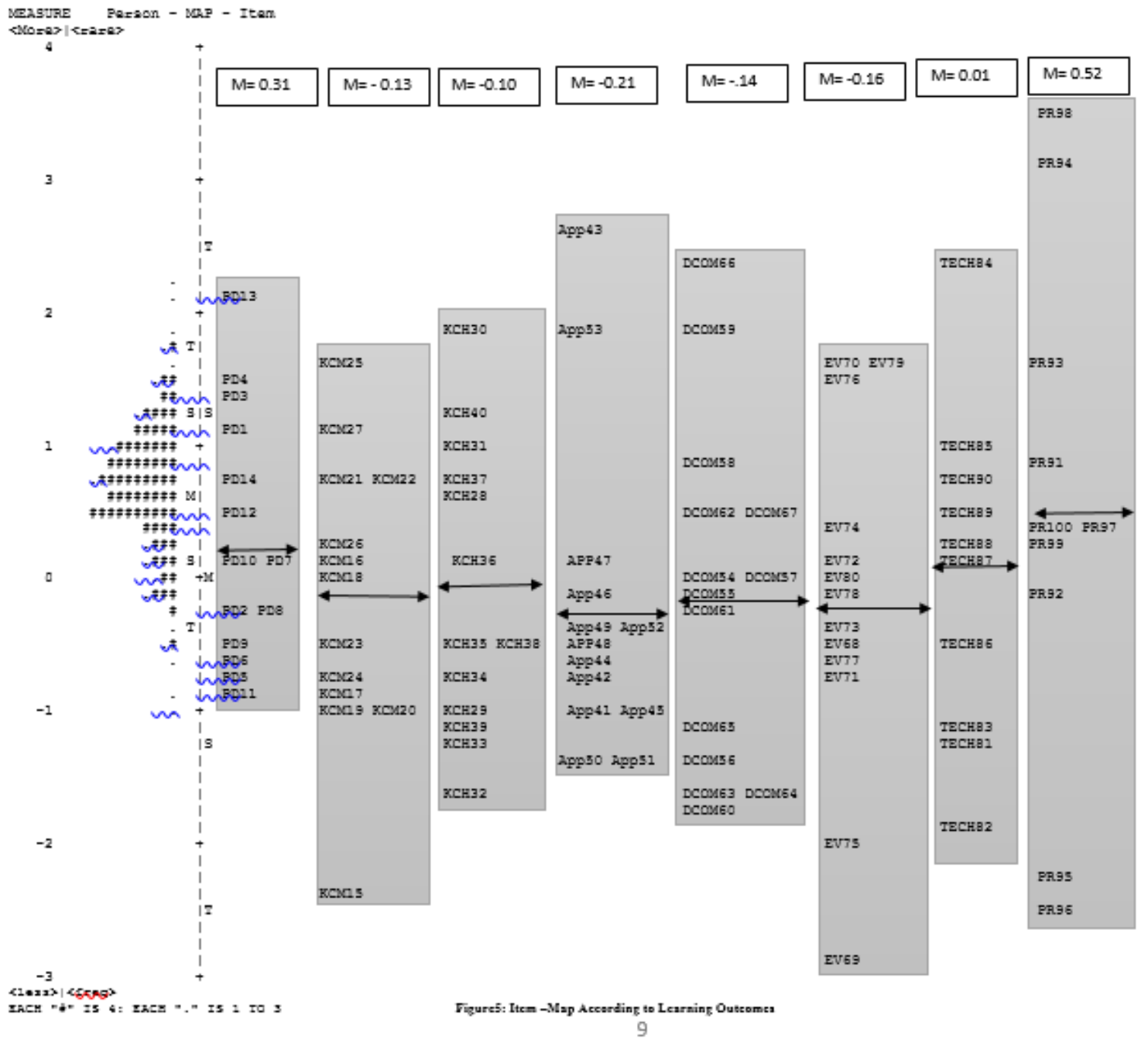

Figure 5: Item -Map According to Learning Outcomes

\section{CONCLUSION}

The Rasch analyses showed that there were few issues related to the adequacy of the exit exam in terms of the items' validity and items' distribution along the interval scale. The items' qualitative investigation revealed that the stems and options of some items have problems. Overall, the students found the exam easy, and the results showed that the mean person ability (0.67 logit) was greater than the item mean $(0.0$ logit). However, the majority of the students were gathered in the middle of the scale showing that students might have a narrow range of ability. Students scored different achievement according to the learning outcomes which they were expected to achieve once they completed the courses of the professional Diploma in Education. This means that they would graduate without mastering certain skills. In principle, the analysis showed a need of a measurement model to validate the items and show how much students have achieved during their study. 


\section{LIMITATION AND STUDY FORWARD}

It is recommended that the existing items should be empirically examined before given to students to ensure the requirements of an accurate measurement, and academic staff and exam writers should be given sufficient training or guidelines on how to prepare and construct accurate and appropriate measurements. The Rasch maps could help the college to see what students can and cannot do because the maps display students and items on the same interval scale. Some of the good items could be added to other coming exit exams to conduct further analysis that ensures comparable exams have obtained as recommended by (Wright, 1993b). This research has its own limitations. The research only focused on the adequacy of the exit exam and students' achievement using the Rasch Model. However, the research did not determine which groups of students performed high or low in the exam. The research did not also examine the factors that might affect students' performance on the exam items such as items format, allocated time, and the number of items.

\section{ACKNOWLEDGEMENT}

The researchers would like to thank the management of the College of Education where the research was conducted for their cooperation and support given to complete the research.

\section{AUTHORS' CONTRIBUTION}

The main Author, Dr. Enas Said Abulibdeh, dealt with the conceptual design, data collection, and preparation of the manuscript. Data analysis, interpretation, and presentation of reports, preparation of the manuscript, and preparation of the final draft have been done by Dr. Kamal J I Badrasawi. Data analysis, interpretation, and presentation of reports and preparation of the final draft have been done by Prof. Noor Lide.

\section{REFERENCES}

1. Bond, T., \& Fox, C. M. (2015). Applying the Rasch Model: fundamental measurement in the human sciences $\left(3^{\text {rd }}\right.$ ed.). Routledge. https://doi.org/10.4324/9781315814698

2. Boone, W. J. (2016). Rasch analysis for instrument development: why, when, and how? CBE—Life Sciences Education, 15(4), rm4. https://doi.org/10.1187/cbe.16-04-0148

3. Creswell, J. W. (2014). Qualitative, quantitative, and mixed methods approaches (4th ${ }^{\text {th }}$ ed.). Sage: USA.

4. Curtis, D. D., \& Boman, P. (2007). X-Ray Your Data with Rasch. International Education Journal, 8(2), 249-259.

5. Engelhard, G. (2000). Historical view of the influences of measurement and reading theories on the assessment of reading. Journal of Applied Measurement, 2(1), 1-26.

6. Green, K. E., \& Frantom, C. G. (2002). Survey development and validation with the Rasch model. Paper presented at the International Conference on Questionnaire Development, Evaluation, and Testing, Charleston, SC.

7. Ingebo, G. S. (1997). Probability in the Measure of Achievement. Chicago, IL: Mesa Press.

8. Kimberlin, C. L., \& Winterstein, A. G. (2008). Validity and reliability of measurement instruments used in research. AMJ Health Syst Pharm, 65(23), 2276-2284. https://doi.org/10.2146/ajhp070364

9. Lee, O. K. (2002). Issues and problems associated with the use of raw scores in interpreting student progress. REACT, 21(1). National Institution of Education: Singapore.

10. Linacre, J. M. (2003). Constructing scientific measurement models. Rasch Measurement Transactions, 17(1), 907.

11. Linacre, J. M. (2018). Winsteps \& Rasch Measurement (Version 4.1.0) [Computer Software and manual]. Retrieved from www.winsteps.com

12. Linacre, J.M. (2019). A User's Guide to Winsteps \& Ministeps (Rasch-Model Computer Programs). Program Manual 4.4.5. www.winsteps.com

13. Gay, L. R., \& Airsian, P. (2012). Educational research: Competencies for analysis and application (10 ${ }^{\text {th }}$ ed.). Boston: Pearson

14. Worthen, B. R., White, K. R., Fan, X., \& Sudweeks, R. R. (1999). Measurement and assessment in schools. Addison Wesley: Longman.

15. Wright, B. D. (1993a). Thinking with raw scores. Rasch Measurement Transactions, 7(2), 299-300.

16. Wright, B. D. (1993b). Equitable test equating. Rasch Measurement Transactions, 7(2), 298-299.

17. Wright, B. D. (1997). A history of social science measurement. Educational Measurement: Issues and Practice, 16(4), 33-52. https://doi.org/10.1111/j.1745-3992.1997.tb00606.x

18. Wright, B.D. (1999). Common sense for measurement. Rasch Measurement Transactions, 13(3), 704-705.

19. Wright, B. D., \& Linacre, J. M. (1997). The Rasch Model as a foundation for the lexile framework. Retrieved from www.lexile.com/lexilearticles/rasch-model.pdf

20. Wright, B. D., \& Stone, M. H. (1979). Best design test: A handbook for Rasch measurement. Chicago: Mesa Press. 
Appendix A1: Item statistics: Entry order

\begin{tabular}{|c|c|c|c|c|c|c|c|c|c|c|c|c|c|}
\hline \multirow{2}{*}{$\begin{array}{l}\text { | ENTRY } \\
\text { | NUMBER }\end{array}$} & TOTAL & TOTAL & & MODEL | & IT & OU' & FIT & | PTMEAS & UR-AL | E & EXACT & MATCH| & & \\
\hline & SCORE & COUNT & MEASURE & S.E. |MNSQ & ZSTD|N & $\mathbb{A N S Q}$ & ZSTD | & | CORR. & EXP. I & OBS\% & EXP\% & Item & \\
\hline & & & & & & & & & & & & & \\
\hline 1 & 131 & 322 & 1.08 & $.12 \mid 1.07$ & $2.3 \mid 1$ & .09 & 2.41 & .09 & .241 & 61.2 & 62.11 & PD1 & \\
\hline 2 & 231 & 322 & -.31 & $.13 \mid 1.07$ & $1.2 \mid 1$ & .14 & 2.11 & .07 & .231 & 73.0 & 72.31 & PD2 & \\
\hline 3 & 109 & 322 & 1.39 & $.12 \mid 1.06$ & $1.5 \mid 1$ & .09 & 1.61 & .10 & .231 & 64.0 & 67.11 & PD3 & \\
\hline 4 & 103 & 322 & 1.47 & $.12 \mid 1.05$ & $1.1 \mid 1$ & .10 & 1.81 & .11 & .221 & 69.6 & 68.61 & PD4 & \\
\hline 5 & 253 & 322 & -.70 & $.14 \mid \quad .97$ & -.31 & .96 & -.41 & .27 & .211 & 78.3 & 78.61 & PD5 & \\
\hline 6 & 248 & 322 & -.60 & $.14 \mid .99$ & -.11 & .97 & -.31 & .24 & .221 & 77.6 & 77.11 & PD 6 & \\
\hline 7 & 201 & 322 & .14 & $.121 \quad .97$ & $-.8 i$ & .97 & -.81 & .29 & $.24 i$ & 68.6 & 64.81 & PD7 & \\
\hline 8 & 226 & 322 & -.23 & .131 .95 & -.91 & .93 & -1.21 & .33 & .231 & 71.4 & 70.91 & PD8 & \\
\hline 9 & 242 & 322 & -.49 & $.13 / 1.06$ & 1.011 & .07 & .91 & .10 & .221 & 74.5 & 75.41 & PD9 & \\
\hline 10 & 202 & 322 & .12 & .121 .98 & -.51 & .98 & -.31 & .27 & .241 & 67.4 & 65.01 & PD10 & \\
\hline 11 & 263 & 322 & -.90 & $.15 \mid 1.00$ & .011 & .03 & .31 & .19 & .201 & 81.4 & $81.7 \mid$ & PD11 & \\
\hline 12 & 172 & 322 & .53 & $.121 \quad .98$ & -.61 & .98 & -.71 & .27 & .241 & 59.9 & 60.11 & PD12 & \\
\hline 13 & 62 & 322 & 2.18 & $.14 \mid 1.01$ & .211 & .12 & 1.21 & .13 & .191 & 81.1 & 80.71 & PD13 & \\
\hline 14 & 160 & 322 & .69 & $.111 \quad .97$ & $-1.1 \mid$ & .97 & -.81 & .29 & .241 & 62.7 & 59.41 & PD14 & \\
\hline 15 & 305 & 322 & -2.33 & $.25 \mid .95$ & -.21 & .63 & $-1.6 \mid$ & .31 & .121 & 94.7 & 94.71 & KCM15 & \\
\hline 16 & 199 & 322 & .17 & $.12 \mid 1.03$ & .811 & .05 & 1.11 & .18 & .241 & 64.3 & 64.41 & KCM1 6 & \\
\hline 17 & 263 & 322 & -.90 & $.15 \mid .97$ & $-.3 \mid 1$ & .00 & .11 & .24 & .201 & 82.0 & $81.7 \mid$ & КСM17 & \\
\hline 18 & 207 & 322 & .05 & $.12 \mid 1.03$ & .811 & .06 & 1.21 & .17 & $.24 \mid$ & 65.5 & 66.11 & KCM18 & \\
\hline 19 & 267 & 322 & -.99 & .15| .99 & -.11 & .97 & -.21 & .22 & .201 & 83.2 & 82.91 & KCM19 & \\
\hline 20 & 270 & 322 & -1.06 & $.15 \mid .90$ & $-1.0 \mid$ & .77 & -2.11 & .42 & .191 & 83.9 & 83.81 & KCM20 & \\
\hline 21 & 156 & 322 & .74 & $.11 \mid 1.03$ & $1.1 \mid 1$ & .03 & 1.11 & .18 & .241 & 56.8 & 59.41 & КСм21 & \\
\hline 22 & 153 & 322 & .78 & $.11 \mid \quad .97$ & $-1.0 \mid$ & .97 & -.91 & .29 & .241 & 62.1 & 59.51 & КСM22 & \\
\hline 23 & 239 & 322 & -.44 & $.131 \quad .95$ & -.71 & .92 & $-1.1 \mid$ & .32 & .221 & 74.5 & 74.61 & КСм23 & \\
\hline 24 & 254 & 322 & -.72 & $.14 \mid .96$ & $-.5 i$ & .90 & -1.01 & .30 & .211 & 79.2 & $78.9 i$ & КСм24 & \\
\hline 25 & 90 & 322 & 1.68 & $.131 \quad .99$ & -.21 & .98 & -.31 & .24 & .211 & 71.1 & 72.21 & КСм25 & \\
\hline 26 & 194 & 322 & .24 & $.121 \quad .99$ & -.41 & .97 & -.81 & .27 & .241 & 62.7 & 63.41 & КСм26 & \\
\hline 27 & 132 & 322 & 1.06 & $.12 \mid 1.03$ & $1.1 \mid 1$ & .04 & 1.21 & .17 & .241 & 60.6 & 61.91 & КСм27 & \\
\hline 28 & 166 & 322 & .61 & $.11 \mid 1.05$ & 1.811 & .05 & 1.61 & .15 & .241 & 54.0 & 59.61 & KCH28 & \\
\hline 29 & 267 & 322 & -.99 & $.15 \mid .97$ & -.31 & .93 & -.51 & .26 & .201 & 83.2 & 82.91 & KCH29 & \\
\hline 30 & 79 & 322 & 1.86 & $.13 / 1.09$ & 1.311 & .19 & 2.21 & .01 & .211 & 74.8 & $75.5 i$ & КСН30 & \\
\hline 31 & 135 & 322 & 1.02 & $.12 \mid 1.01$ & .311 & .01 & .21 & .22 & .241 & 63.4 & $61.4 i$ & Ксн31 & \\
\hline 32 & 291 & 322 & -1.67 & $.191 \quad .98$ & $-.1 \mid$ & .92 & -.41 & .20 & .161 & 90.4 & 90.41 & КСH32 & \\
\hline 33 & 279 & 322 & -1.29 & $.17 \mid 1.02$ & .211 & .05 & .41 & .14 & .181 & 86.6 & 86.61 & КСН33 & \\
\hline 34 & 257 & 322 & -.78 & $.14 \mid .96$ & $-.4 i$ & .93 & -.71 & .29 & .211 & 80.7 & 79.81 & КСН34 & \\
\hline 35 & 243 & 322 & -.51 & .131 .95 & $-.8 i$ & .96 & -.41 & .31 & .221 & 77.0 & $75.7 \mid$ & КСН35 & \\
\hline 36 & 200 & 322 & .15 & $.121 \quad .99$ & -.11 & .99 & -.11 & .25 & .241 & 66.5 & 64.61 & КСH 36 & \\
\hline 37 & 151 & 322 & .81 & $.12 \mid 1.00$ & $.2 \mid 1$ & .00 & -.11 & .24 & .241 & 56.5 & 59.61 & КСH37 & \\
\hline 38 & 244 & 322 & -.53 & $.131 \quad .97$ & -.31 & .97 & -.31 & .27 & .221 & 75.5 & 76.01 & КСH38 & \\
\hline 39 & 274 & 322 & -1.16 & $.16 \mid \quad .95$ & $-.4 i$ & .88 & -1.01 & .29 & .191 & 85.1 & 85.11 & КСН39 & \\
\hline 40 & 119 & 322 & 1.24 & $.121 \quad .99$ & $-.1 \mid 1$ & .00 & .01 & .24 & .231 & 66.8 & 64.61 & $\mathrm{KCH} 40$ & \\
\hline 41 & 267 & 322 & -.99 & $.15 \mid 1.01$ & .211 & .12 & 1.01 & .13 & .201 & 83.2 & 82.91 & App 41 & \\
\hline 42 & 253 & 322 & -.70 & $.14 \mid .97$ & -.31 & .94 & -.61 & .27 & .211 & 78.9 & 78.61 & App 42 & I \\
\hline 43 & 42 & 322 & 2.66 & $.17 \mid 1.09$ & $.8 \mid 1$ & .49 & 3.01 & $\mid-.12$ & .161 & 87.0 & 86.91 & App 43 & \\
\hline 44 & 247 & 322 & -.58 & $.14 \mid 1.00$ & .01 & .94 & -.71 & | $\quad .24$ & .221 & 75.5 & 76.91 & App 4 4 & \\
\hline 45 & 266 & 322 & -.97 & $.15 \mid .96$ & $-.4 i$ & .97 & -.21 & .27 & .201 & 82.9 & 82.61 & App 45 & i \\
\hline 46 & 219 & 322 & -.12 & $.121 \quad .97$ & -.61 & .95 & -.81 & .29 & .231 & 68.9 & 69.01 & App 6 & \\
\hline 47 & 204 & 322 & .10 & $.121 \quad .99$ & -.21 & .97 & $-.7 \mid$ & .27 & .241 & 63.0 & 65.51 & App 47 & \\
\hline 48 & 245 & 322 & -.55 & $.131 \quad .97$ & -.31 & .94 & -.71 & .28 & .221 & 77.0 & 76.31 & App 48 & \\
\hline 49 & 232 & 322 & -.33 & $.13 / 1.10$ & $1.7 \mid 1$ & .14 & 2.01 & .02 & .231 & 68.9 & 72.61 & App 49 & \\
\hline 50 & 283 & 322 & -1.41 & $.171 \quad .98$ & $-.1 i$ & .93 & -.41 & .22 & $.17 i$ & 87.9 & 87.91 & App50 & \\
\hline 51 & 280 & 322 & -1.32 & $.17 \mid .94$ & $-.5 i$ & .83 & -1.21 & .32 & .181 & 87.0 & 86.91 & App51 & \\
\hline 52 & 235 & 322 & -.38 & $.13 \mid .95$ & -.91 & .92 & -1.11 & .33 & .221 & 74.5 & $73.4 \mid$ & App 52 & \\
\hline 53 & 79 & 322 & 1.86 & $.13 \mid .96$ & $-.5 i$ & .93 & -.91 & .28 & .211 & 75.5 & 75.51 & App53 & \\
\hline 54 & 209 & 322 & .02 & $.121 \quad .99$ & $-.2 \mid 1$ & .01 & .31 & .24 & .241 & 68.0 & 66.61 & OM54 & \\
\hline 55 & 219 & 322 & -.12 & $.12 \mid 1.08$ & $1.7 \mid 1$ & .14 & 2.31 & .06 & .231 & 68.3 & 69.01 & DCOM55 & \\
\hline 56 & 284 & 322 & -1.44 & $.18 \mid 1.01$ & $.1 \mid 1$ & .08 & .61 & .14 & .171 & 88.2 & 88.21 & DCOM56 & 1 \\
\hline 57 & 209 & 322 & .02 & $.121 \quad .97$ & $-.7 i$ & .96 & -.91 & .30 & .241 & 66.8 & 66.61 & DCOM57 & 1 \\
\hline 58 & 150 & 322 & .82 & $.121 \quad .98$ & -.91 & .97 & -1.01 & | .29 & .241 & 59.3 & $59.7 \mid$ & DCOM58 & \\
\hline 59 & 79 & 322 & 1.86 & $.13 \mid 1.10$ & $1.6 \mid 1$ & .20 & 2.41 & -.02 & .211 & 74.8 & 75.51 & DCOM59 & 1 \\
\hline 60 & 294 & 322 & -1.79 & $.20 \mid 1.01$ & $.1 \mid 1$ & .09 & .51 & | .11 & .151 & 91.3 & 91.31 & DCOM60 & \\
\hline 61 & 227 & 322 & -.25 & $.13 / 1.03$ & .611 & .02 & .41 & .18 & .231 & 69.9 & 71.21 & DCOM61 & \\
\hline 62 & 177 & 322 & .47 & $.12 \mid 1.03$ & $.9 \mid 1$ & 1.03 & 1.01 & .19 & .241 & 58.1 & 60.61 & DCOM 62 & \\
\hline 63 & 291 & 322 & -1.67 & $.191 \quad .93$ & -.41 & .76 & -1.41 & .34 & .161 & 90.4 & 90.41 & DCOM 63 & \\
\hline 64 & 288 & 322 & -1.57 & $.18 \mid .99$ & .01 & .95 & -.21 & .20 & .161 & 89.4 & 89.41 & DCOM64 & \\
\hline 65 & 275 & 322 & -1.18 & $.16 \mid \quad .94$ & $-.5 i$ & .96 & -.31 & .29 & .191 & 85.4 & $85.4 i$ & DCOM65 & \\
\hline 66 & 55 & 322 & 2.34 & $.15 \mid .95$ & $-.5 i$ & .92 & -.71 & .28 & .181 & 82.9 & 82.91 & DCOM6 6 & \\
\hline 67 & 176 & 322 & .48 & $.12 \mid 1.03$ & $1.1 \mid 1$ & .04 & 1.21 & .18 & .241 & 59.0 & $60.5 i$ & DCOM 67 & \\
\hline 68 & 244 & 322 & -.53 & $.13 \mid .95$ & -.81 & .89 & $-1.3 \mid$ & .34 & .221 & 76.1 & 76.01 & EV68 & \\
\hline 69 & 312 & 322 & -2.90 & $.321 \quad .95$ & -.11 & .56 & $-1.4 i$ & .29 & $.10 i$ & 96.9 & 96.91 & EV69 & \\
\hline 70 & 90 & 322 & 1.68 & $.13 \mid 1.03$ & .611 & .08 & 1.21 & .13 & .211 & 73.0 & 72.21 & EV70 & \\
\hline 71 & 255 & 322 & -.74 & $.14 \mid \quad .95$ & $-.7 i$ & .89 & -1.21 & .33 & .211 & 79.5 & 79.21 & EV71 & \\
\hline 72 & 206 & 322 & .07 & $.12 \mid 1.07$ & $1.6 \mid 1$ & .07 & 1.51 & .11 & .241 & 64.0 & 65.91 & EV72 & \\
\hline 73 & 232 & 322 & -.33 & .131 .99 & -.11 & .99 & -.11 & .24 & .231 & 72.7 & 72.61 & EV73 & \\
\hline 74 & 185 & 322 & .36 & .121 .97 & -.91 & .96 & -1.11 & .30 & .241 & 61.2 & 61.81 & EV74 & \\
\hline 75 & 300 & 322 & -2.05 & .221 & -.21 & .88 & -.51 & .24 & .141 & 93.2 & 93.21 & EV75 & \\
\hline 76 & 102 & 322 & 1.49 & $.121 \quad .96$ & $-.9 i$ & .95 & -.81 & .30 & .221 & 71.7 & 68.91 & EV76 & \\
\hline
\end{tabular}




\begin{tabular}{|c|c|c|c|c|c|c|c|c|c|c|c|c|c|c|}
\hline | & 77 & 250 & 322 & -.64 & $.14 \mid 1$ & .00 & .01 & .97 & -.31 & .23 & .211 & 77.3 & 77.71 & EV77 \\
\hline | & 78 & 219 & 322 & -.12 & .121 & .97 & $-.7 \mid$ & .98 & -.41 & .29 & .231 & 70.8 & 69.01 & EV78 \\
\hline | & 79 & 93 & 322 & 1.63 & $.13 \mid 1$ & .05 & .911 & .09 & 1.31 & .11 & .221 & 70.8 & 71.41 & EV79 \\
\hline | & 80 & 209 & 322 & .02 & .121 & .92 & -2.01 & .90 & -2.21 & .40 & .241 & 70.5 & 66.61 & EV80 \\
\hline | & 81 & 279 & 322 & -1.29 & .171 & .94 & -.51 & .88 & -.81 & .30 & .181 & 86.6 & 86.61 & ТЕСН81। \\
\hline | & 82 & 297 & 322 & -1.91 & .211 & .93 & -.41 & .74 & -1.31 & .33 & $.15 \mid$ & 92.2 & 92.21 & TECH82 \\
\hline | & 83 & 272 & 322 & -1.11 & $.16 \mid 1$ & .01 & $.1 \mid 1$ & .11 & .91 & .13 & .191 & 84.5 & 84.51 & ТЕСН83| \\
\hline i & 84 & 53 & 322 & 2.38 & $.15 i 1$ & .05 & .611 & .21 & $1.7 i$ & .03 & .181 & 83.5 & 83.51 & TECH84 \\
\hline I & 85 & 137 & 322 & 1.00 & $.12 \mid 1$ & .08 & $2.5 \mid 1$ & .11 & 3.01 & .08 & .241 & 57.8 & 61.11 & TECH85 \\
\hline I & 86 & 243 & 322 & -.51 & .131 & .97 & -.51 & .92 & -.91 & .29 & .221 & 76.4 & 75.71 & TECH86 \\
\hline । & 87 & 202 & 322 & .12 & .121 & .98 & -.51 & .97 & -.61 & .28 & .241 & 64.9 & 65.01 & ТЕСН87 \\
\hline i & 88 & 197 & 322 & .19 & $.12 \mid 1$ & .09 & $2.4 \mid 1$ & .10 & 2.41 & .07 & .241 & 59.0 & 64.01 & TECH88 \\
\hline I & 89 & 174 & 322 & .51 & .121 & .99 & -.31 & .99 & $-.4 i$ & .26 & .241 & 59.3 & 60.31 & ТЕСН89 \\
\hline i & 90 & 155 & 322 & .76 & $.11 \mid 1$ & .05 & $1.9 \mid 1$ & .06 & 1.91 & .14 & .241 & 55.3 & 59.51 & ТЕСН90। \\
\hline I & 91 & 148 & 322 & .85 & $.12 \mid 1$ & .12 & $4.4 \mid 1$ & .13 & 3.91 & .01 & .241 & 49.7 & 59.81 & PR91 \\
\hline I & 92 & 220 & 322 & -.14 & .1211 & .00 & $.1 \mid 1$ & .01 & .21 & .22 & .231 & 69.3 & 69.31 & PR92 \\
\hline I & 93 & 92 & 322 & 1.64 & .131 & .98 & -.311 & .00 & .01 & .25 & .221 & 71.7 & 71.71 & PR93 \\
\hline I & 94 & 29 & 322 & 3.09 & .2011 & .01 & $.1 \mid 1$ & .03 & .21 & .12 & . 141 & 91.0 & 91.01 & PR94 \\
\hline I & 95 & 304 & 322 & -2.27 & .241 & .99 & .01 & .93 & -.21 & .15 & .131 & 94.4 & 94.41 & PR95 \\
\hline I & 96 & 307 & 322 & -2.47 & .271 & .93 & -.21 & .67 & $-1.3 \mid$ & .31 & .121 & 95.3 & 95.31 & PR96 \\
\hline i & 97 & 188 & 322 & .32 & .121 & .94 & -2.01 & .92 & -2.21 & .37 & .241 & 65.8 & 62.31 & PR97 \\
\hline i & 98 & 19 & 322 & 3.56 & $.24 \mid 1$ & .04 & .311 & .50 & 1.91 & -.07 & .111 & 94.1 & 94.11 & PR98 \\
\hline | & 99 & 190 & 322 & .29 & .1211 & .05 & $1.4 \mid 1$ & .05 & 1.41 & .15 & .241 & 60.2 & 62.61 & PR99 \\
\hline & 100 & 187 & 322 & .33 & .121 & .94 & -1.81 & .93 & -1.91 & .35 & .241 & 63.7 & 62.11 & PR100 \\
\hline & & & & & & & & & & & & & & \\
\hline & & 202.1 & 322.0 & .00 & $.14 \mid 1$ & .00 & $.1 \mid$ & .99 & $.1 \mid$ & & & 74.1 & 74.31 & \\
\hline & & 72.9 & 0 & 1.25 & .041 & .05 & 1.01 & .13 & 1.31 & & I & 11.2 & 10.71 & \\
\hline
\end{tabular}

Appendix A2: Person Statistics: Misfit Order

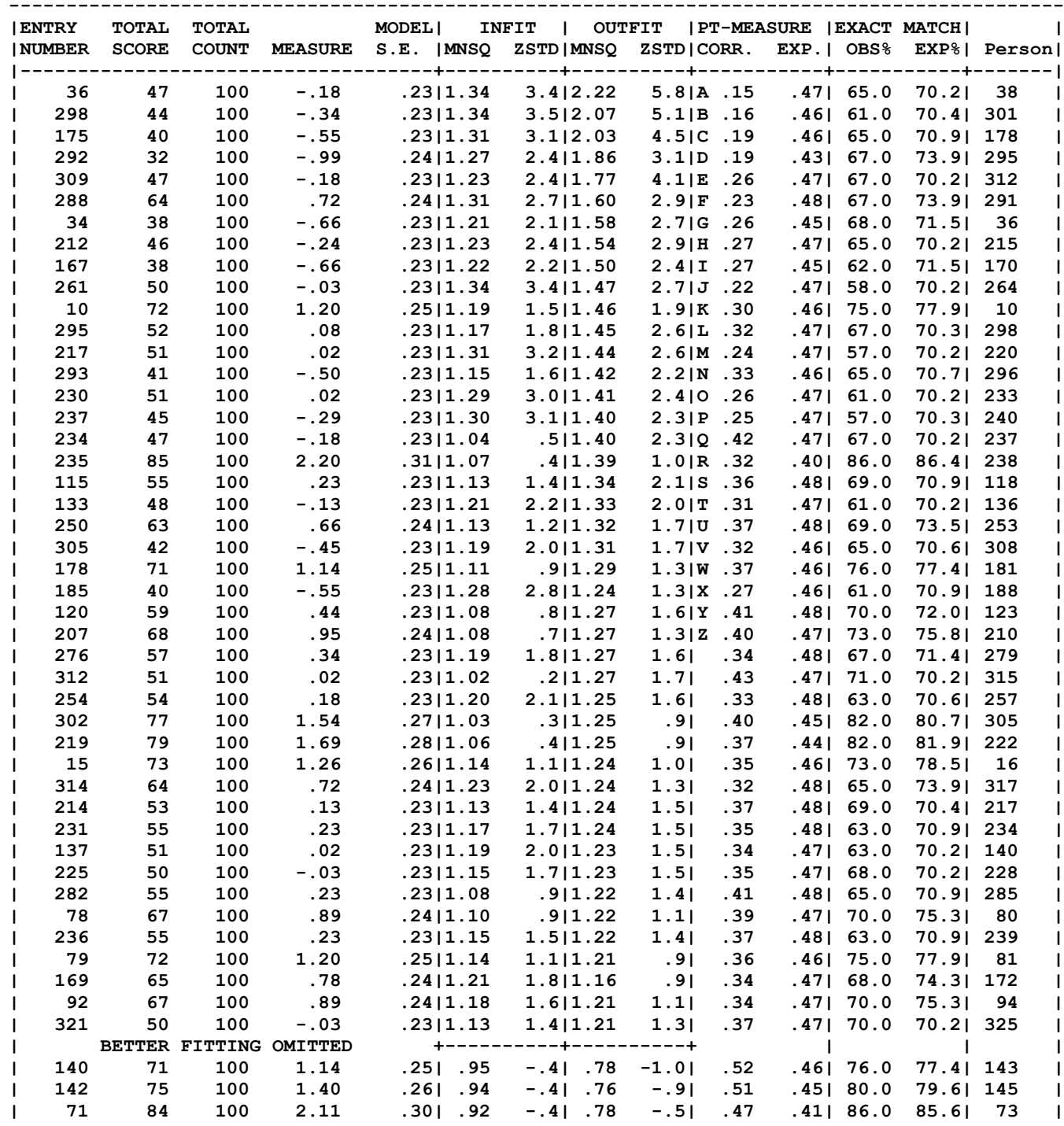


Humanities \& Social Sciences Reviews

elSSN: 2395-6518, Vol 8, No 2e, 2020, pp 179-189

https://doi.org/10.18510/hssr.2020.82e22

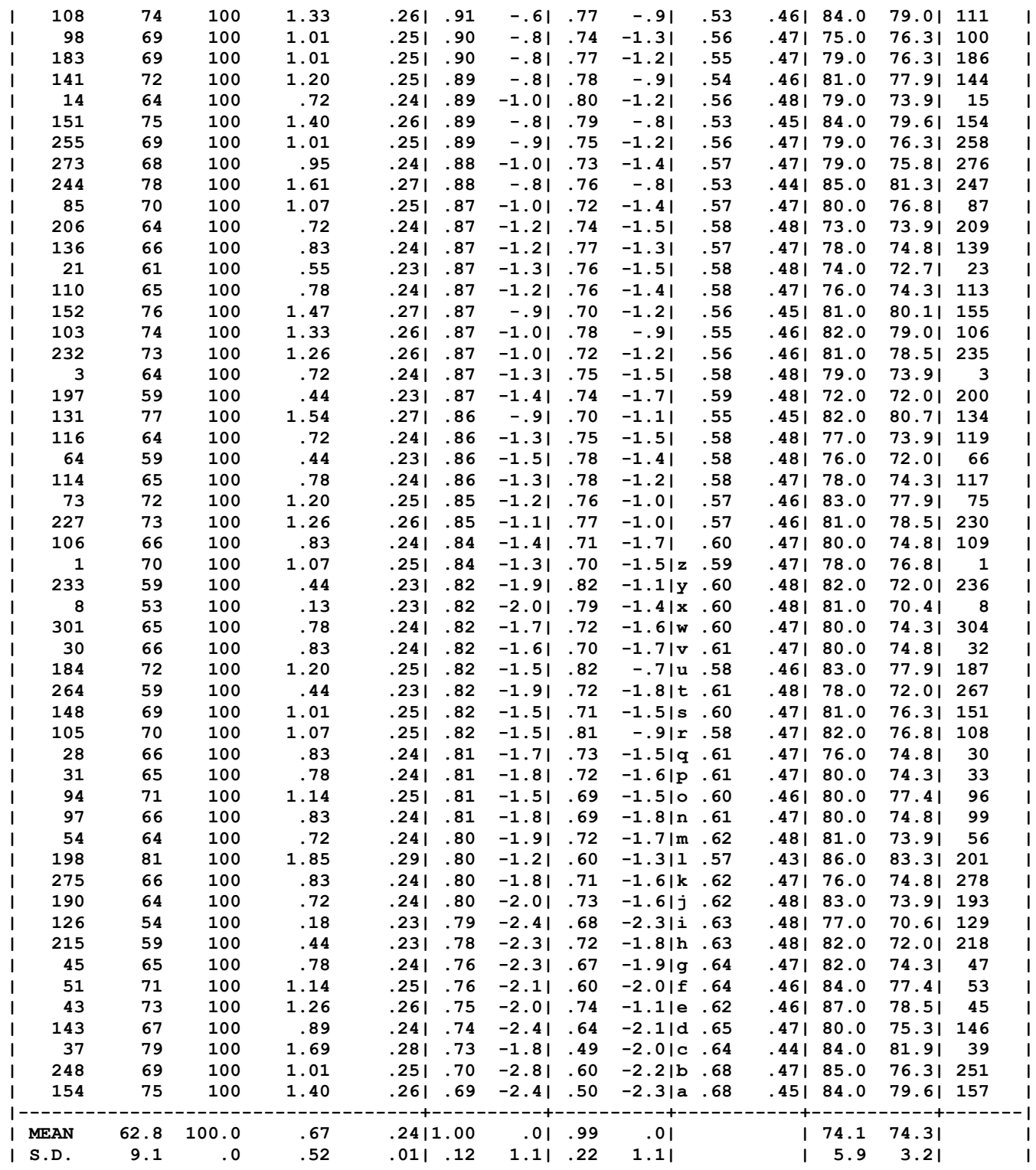

